\title{
Identification of arginine- and lysine-methylation in the proteome of Saccharomyces cerevisiae and its functional implications
}

\author{
Chi Nam Ignatius Pang ${ }^{1,2}$, Elisabeth Gasteiger ${ }^{3}$, Marc R Wilkins ${ }^{1,2^{*}}$
}

\begin{abstract}
Background: The methylation of eukaryotic proteins has been proposed to be widespread, but this has not been conclusively shown to date. In this study, we examined 36,854 previously generated peptide mass spectra from 2,607 Saccharomyces cerevisiae proteins for the presence of arginine and lysine methylation. This was done using the FindMod tool and 5 filters that took advantage of the high number of replicate analysis per protein and the presence of overlapping peptides.

Results: A total of 83 high-confidence lysine and arginine methylation sites were found in 66 proteins. Motif analysis revealed many methylated sites were associated with $\mathbf{M K}, \mathbf{R G G / R X G / R G X}$ or WXXXR motifs. Functionally, methylated proteins were significantly enriched for protein translation, ribosomal biogenesis and assembly and organellar organisation and were predominantly found in the cytoplasm and ribosome. Intriguingly, methylated proteins were seen to have significantly longer half-life than proteins for which no methylation was found. Some $43 \%$ of methylated lysine sites were predicted to be amenable to ubiquitination, suggesting methyl-lysine might block the action of ubiquitin ligase.

Conclusions: This study suggests protein methylation to be quite widespread, albeit associated with specific functions. Large-scale tandem mass spectroscopy analyses will help to further confirm the modifications reported here.
\end{abstract}

\section{Background}

The methylation of proteins is of increasing biological interest. It is predominantly found on lysine and arginine residues, but has also been found on histidine, glutamic acid and on the carboxyl groups of proteins (reviewed in Grillo and Colombatto 2005) [1]. Methylation of lysine involves the addition of one to three methyl groups on the amino acid's $\varepsilon$-amine group, to form mono-, di- or tri-methyllysine. Its function is best understood in histones. Methylation on the tails of histone proteins, in conjunction with acetylation and phosphorylation, controls their interaction with other proteins, affects chromatin compaction and the up- or down-regulation of gene expression [2]. For S. cerevisiae, lysine methylation is found in histone $\mathrm{H} 3$ and histone H4 [3]. Tri-methylation at H3K4 and H3K36 is

\footnotetext{
*Correspondence: marc.wilkins@unsw.edu.au

${ }^{1}$ School of Biotechnology and Biomolecular Sciences, University of New South Wales, Sydney, NSW, 2052, Australia
}

positively correlated with gene activity [4], while H3K79 are involved in gene silencing [5,6]. Histone H3K79 methylation is evolutionarily conserved and is involved in several pathways, including Sir protein-mediated heterochromatic gene silencing [7]. meiotic checkpoint control [8] and in the G1 and S phase DNA damage checkpoint functions of Rad9p $[9,10]$. While studies of lysine methylation have mainly focused on histone proteins, several non-histone proteins are also known to be lysine-methylated. They are mainly ribosomal proteins or proteins involved in protein translation [11], and include Rpl12p [12,13], Rpl23p [12,14], Rpl42p [15], and eEF1Ap [16].

The methylation of arginine involves the addition of one or two methyl groups to the amino acid's guanidino group, forming mono- or di-methylarginine. It is predominantly known to be associated with RNA regulation and processing [17]. In S. cerevisiae, Hmt1p is a type 1 arginine methyltransferase that catalyses the formation

\section{South Wales, Sydney, NSW, 2052, Australia}

( 2010 Pang et al; licensee BioMed Central Ltd. This is an Open Access article distributed under the terms of the Creative Commons Attribution License (http://creativecommons.org/licenses/by/2.0), which permits unrestricted use, distribution, and reproduction in any medium, provided the original work is properly cited. 
of mono- and asymmetric di-methylarginine. This enzyme is known to methylate a number of proteins that contain an RGG-motif; these include Npl3p, Hrp1p, Nab2p, Gar1p, Nop1p, Nsr1p, Yra1p, Sbp1p, and Hrb1p. These proteins have been implicated in poly(A)+ mRNA binding, processing and export [17], ribosome biogenesis [18-20] and gene silencing [21]. Moreover, methylation is required for the nuclear export of RNA binding proteins Npl3p, Hrp1p, and Nab2p [22,23]. The repeated RGG-motif was known as a RNA-binding motif [24], and this also supports the role of arginine methylation in the regulation of mRNA binding [25]. The methylation of nuclear shuttling proteins is suggested to weaken their binding with cargo proteins and disrupt their export from the nucleus [26]. Arginine methylation is also known to facilitate or block protein-protein interactions. Arginine methylation of $\mathrm{SmB}$ protein facilitates the binding of tudor domains in SMN, SPF30, and TDRD3 proteins [27]. In contrast, arginine methylation of Sam68 blocks the interaction of nearby proline-rich motif with an SH3 domain, but not to a WW domain [28]. More examples on methylarginine-regulated interactions are reviewed in McBride and Silver (2001) [29] and Bedford and Clarke (2009) [30].

There have been several studies to identify arginine or lysine-methylated proteins on a proteome-wide scale. In the first of these studies, arginine-methylated protein complexes were purified from HeLa cell extracts using anti-methylarginine antibodies specific against RG-rich sequences [31]. This resulted in the identification of over 200 arginine-methylated proteins, involved in premRNA processing, protein translation, and DNA transcription. However the actual methylation sites on these proteins remain unknown [32]. The second study utilised stable isotope labelling by amino acid in cell culture (SILAC), in which $\left[{ }^{13} \mathrm{CD}_{3}\right]$ methionine was converted to $\left[{ }^{13} \mathrm{CD}_{3}\right] \mathrm{S}$-adenosyl methionine, the substrate for arginine and lysine methylation [32]. Advantages of this method included increased confidence of identification, a capacity to distinguish between trimethylation and acetylation which are near-isobaric, and the ability to quantify the relative changes in methylation status of a protein between two samples. In combination with anti-methyllysine and anti-methylarginine antibody immunoprecipitation techniques, Ong et al. (2004) [32] was able to identify methylation on histones from HeLa cell extracts, such as on histone H3K27. Around 30 other proteins were also found to be methylated at RG-rich motifs and most of these proteins are RNA binding or associated with mRNA processing pathways. The third study used anti-methyllysine antibodies to search for organ-specific lysine methylation in Mus musculus [33]. Proteomic analysis of brain tissue extract by 2-D PAGE, western blotting, and MALDI-ToF peptide mass fingerprinting identified the following lysine-methylated proteins: neurofilament triplet-I protein, Hsc70 protein, creatine kinase, $\alpha$-tubulin, $\alpha$-actin, $\beta$-actin, and $\gamma$-actin. Furthermore, $\alpha$-actin and creatine kinase were found to be methylated in muscle tissue.

The use of tandem mass spectrometry to discover new protein post-translational modifications is common [34]. However, peptide mass fingerprinting can also be used to search for new PTM sites [35]. The FindMod program [35] caters for this approach. It requires peptide mass spectra from a mostly pure protein, for example a spot from 2-D gel, and examines experimental peptide masses for differences in mass with theoretical peptides for that protein that correspond to post-translational modification. Peptides that are potentially modified are checked to see if they contain amino acids that can carry the modification. Where very high accuracy peptide mass measurements can be made, for example with new instruments like the prOTOF2000, high confidence predictions are possible. Parent-ion masses from tandem mass spectrometry data can also be used in FindMod, where it may serve as an initial screen for PTMs before employing more sophisticated and computationally expensive methods [36,37].

Here we describe a strategy for the discovery of methylation on a global scale, using peptide mass fingerprinting data, and implement this to search for methylated lysine and arginine residues in the yeast proteome. A proteome-scale set of MALDI-ToF mass spectra [38] was analysed for putative methylated peptides. The application of 5 filters yielded high-confidence methylation sites that were then further investigated to understand where they are found in protein sequences and their likely function.

\section{Results}

\section{Large-scale methylation discovery in yeast peptide mass} spectra

FindMod was used to analyse peptide mass spectra for 2,607 yeast proteins out of a total $\sim 6,500$ (representing $40 \%$ of the total proteome) for the presence of monoand di-methylation. A tailor-made mass tolerance was calculated for each spectrum to reduce spurious peptide matches; the average of this for all spectra was \pm 0.04 $\mathrm{Da}$. Of all the 24,105 FindMod queries, there were 17,471 matches to potentially methylated peptides (Figure 1). Five filtering strategies, used sequentially, were then applied to this set to find methylation sites of very high confidence. The first filter removed peptides that matched to unmodified peptide sequences as these peptide masses are likely to be unmodified peptides. Conversely, peptides masses that did not match to unmodified peptide sequences are likely to be modified, and these were analysed with the second filter. The 
second filter removed any peptides that contained D or E residues, as artifactual methylation may result from partial methyl esterification of D or E residues [39]. The third filter was designed to take advantage of redundancy within each FindMod output, by removing oneoff or spurious mass spectra. It searched for modifications that were found in two or more overlapping peptides (Figure 2), and took advantage of the reduced efficiency of tryptic cleavage at methylated residues [32], where overlapping peptides with missed cleavages were likely to be found. The fourth filter reduced FindMod false positives by considering whether modifications found by FindMod were unambiguous or ambiguous. An unambiguous modification had only one FindMod match against one query peptide mass (Additional File 1 ), an ambiguous modification had more than one match against a query mass (Additional File 1). For the peptide to be included in the final set of methylated peptides, at least one peptide in the overlapping peptides had to be an unambiguous peptide match. The use of these 4 filters resulted in 169 high confidence methylated peptides, from 17,471 initial low confidence matches (Figure 1).

While overlapping peptides helped localise methylation sites to one or more peptides, they did not necessarily localise the methylation to one amino acid. To address this, we used a fifth filter. When two or more modified peptides that passed filters 1-4 were also found to overlap and share the same modification site, the modification was classified as high confidence and kept. Note that any results for lysine trimethylation were discarded from the study since it is near-isobaric to lysine acetylation. From this filtering process, we found 40 lysine-methylated proteins with 45 lysine methylation sites: 25 with mono- and 20 with di-methylation. Similarly, we found 31 arginine-methylated proteins with 38 arginine methylation sites: 20 with mono- and 18 with di-methylation. There were 5 proteins that contained both arginine and lysine methylation. The list of high confidence methylated proteins and methylation sites are shown in Table 1, additional information on these high confidence methylated peptides and methylation sites are shown in Additional file 2 and Additional file 3 correspondingly.

\section{Confirmation of FindMod protein methylation}

To establish the accuracy of our methylation discovery approach, we theoretically digested all known methylated proteins in Swiss-Prot and analysed the resulting peptides with our FindMod approach. We supplemented this with a larger set of theoretically methylated proteins. The average true positive rate for FindMod at 0.04 Da was $89 \%$. For methylation sites in Swiss-Prot, FindMod had a true positive rate of $100 \%$ for monomethyl$\mathrm{K}, 98 \%$ for dimethyl-K, and $76 \%$ for dimethyl-R (Table 2a). The true positive rate for monomethyl- $\mathrm{R}$ could not be accurately estimated since the number of test cases was insufficient for accurate evaluation. Similarly, the true positive rate for the artificial methylation set was $78 \%$ for monomethyl-K, $89 \%$ for dimethyl-K, and $90 \%$ for both monomethyl-R and dimethyl-R (Table $2 \mathrm{~b}$ ). Additional results for the evaluation of the true positive rate of FindMod are shown in Additional file 4.

To further assess the accuracy of the FindMod approach, methylation sites discovered by FindMod were cross-referenced with known methylation sites in the literature and databases. Whilst only a small number of proteins are documented as methylated in the literature, we confirmed 3 proteins (Ssb1p, Ssb2p, Tub2p) as methylated (Table 3). If we included methyl-lysine sites in peptides containing $\mathrm{D}$ and $\mathrm{E}$, we also confirmed the methylation of Tef1p and Rpl23p. This included 3 lysine methylation sites (K30, K79, and K390) from Tef1p, and 1 lysine dimethylation site (K110) from Rpl23p [14] (Additional file 5). Furthermore, we found 15 methylated ribosomal proteins in S. cerevisiae, consistent with the presence of methylation sites in ribosomal proteins of eukaryotes, such as S. cerevisiae [12-15,40], S. pombe [41], A. thaliana [42], and human [43-46].

\section{Discovery rate of methylated peptides, unmodified} peptides, and lysine and arginine-methylated residues

The discovery rate of a peptide is the frequency of protein identifications in which a particular peptide is observed. Methylated peptides with low discovery rates are likely to be sub-stoichiometric and partially methylated. It was predicted that there should be many more unmodified peptides than methylated peptides, and that methylated peptides will have a lower discovery rate since they are likely to be sub-stoichiometric. The discovery rate of high confidence methylated peptides was found to be significantly lower than that of unmodified peptides $(\mathrm{p}<0.0001)$. The median discovery rate for unmodified peptides was 0.50 , and the median value for arginine and lysine methylated peptides was 0.03 . To check that the lower discovery rate of methylated residues was not due to differences in peptide ionisation efficiency, we examined if there was a correlation between the discovery rates of methylated and unmodified residues. In the set of results, there were 69 methylated residues for which the corresponding unmodified residues were also seen. The discovery rate of methylated residues was significantly but weakly correlated with the discovery rate of matching unmodified residues (Kendall's $\tau=0.22, \mathrm{p}<0.01$ ), consistent with expected. A list of methylated proteins and the methylation sites discovered by FindMod is shown in Table 1. The discovery rate of all high confidence methylated peptides and methylation sites are shown in Additional file 2 and Additional file 3 correspondingly. 


\section{7,471 peptides}

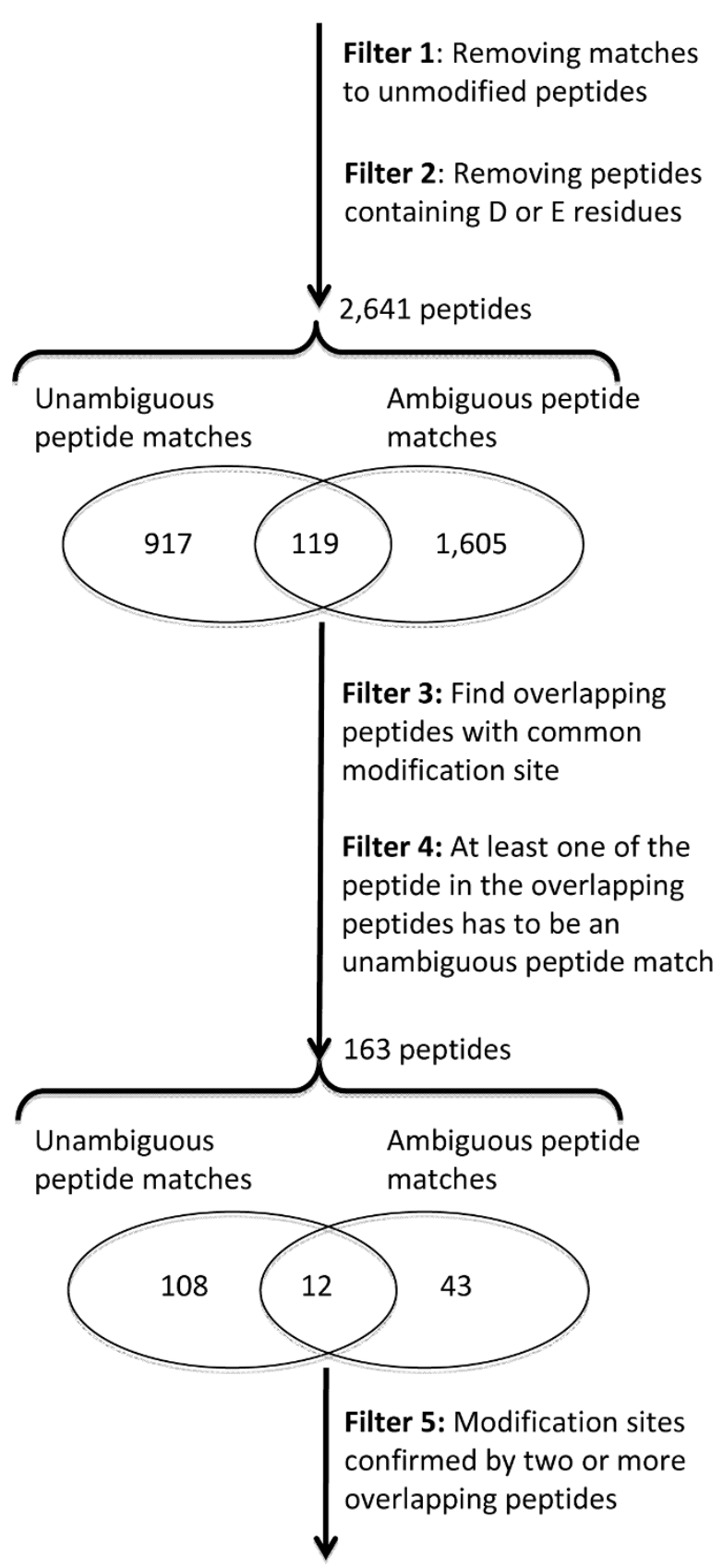

45 lysine methylation sites,

38 arginine methylation sites

Figure 1 Finding high confidence modified peptides using 5 filtering strategies. By removing peptides that matched to both methylated peptides and unmodified peptides (filter 1) and peptides which contains D or E residues (filter 2), 2,641 peptides were left. By filtering for overlapping peptides (filter 3), and where at least one of the overlapping peptide is an unambiguous peptide match (filter 4), 163 peptides remained. These included 108 unambiguous peptide matches, 43 ambiguous peptide matches, and 12 peptides in both categories. Found in these peptides are 45 lysine methylation sites and 38 arginine methylation sites, all of which are of high confidence (filter 5). 


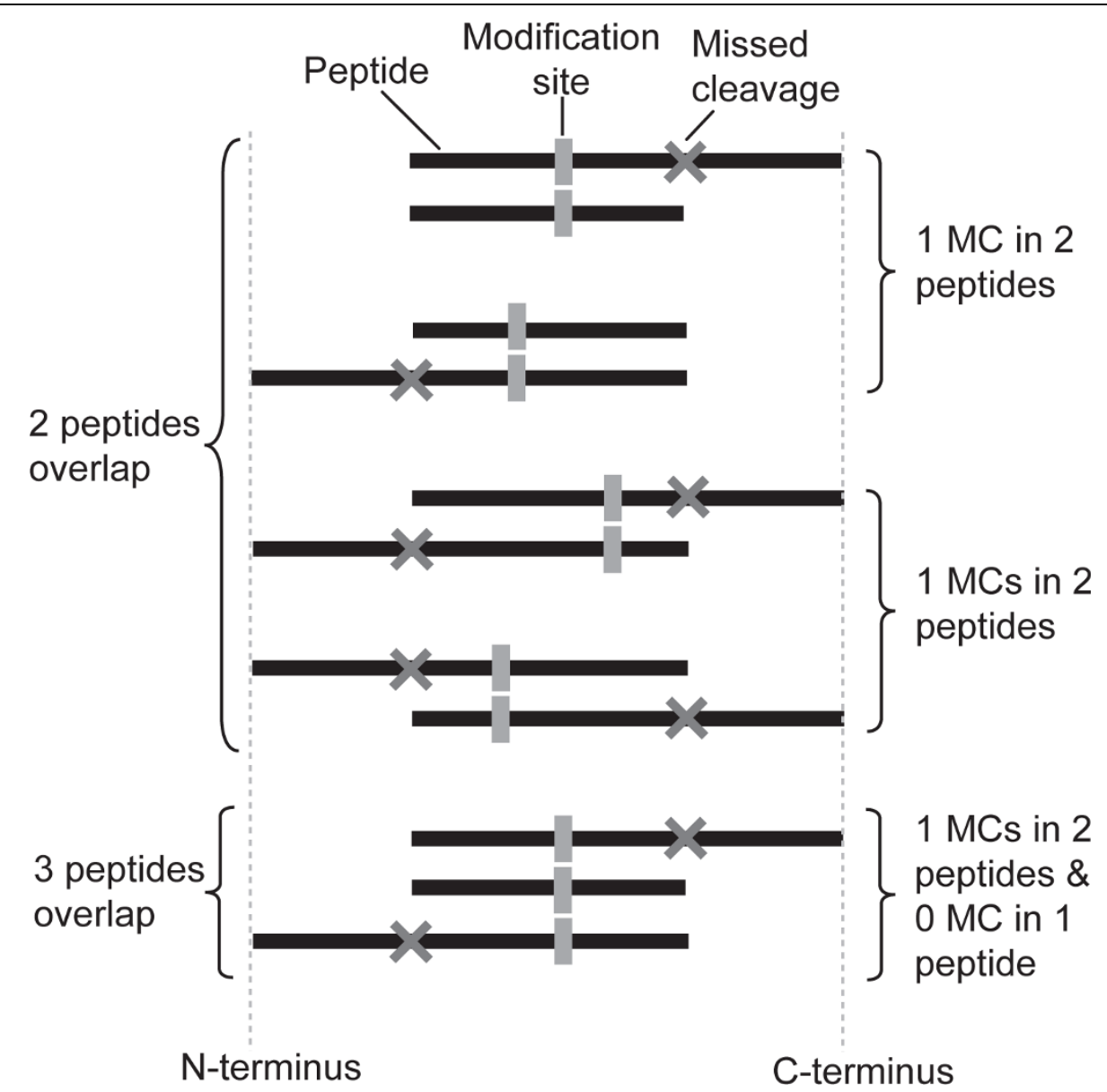

Figure 2 Filter 2: using two or more overlapping peptides to improve modification confidence. A peptide can have no missed cleavage or one missed cleavage $(\mathrm{MC})$ at either the $\mathrm{N}$-terminus or C-terminus of the peptide. The modification site has to be found in two or more overlapping peptides for it to be accepted for subsequent analyses. There are a few scenarios where these modification sites can be found. a) There can be one peptide with no missed cleavage overlapping with another peptide with one missed cleavage. b) The modification site can be found in two overlapping peptides each with one missed cleavage. c) In the third scenario, the modification site may be found in three peptides, one peptide with no missed cleavage, and two peptides with one missed cleavage each. In all of the above cases, at least one peptide in the overlapping peptides has to be an unambiguous peptide match. Cases where this was not seen were excluded from all subsequent analyses.

Biological function, sub-cellular localization, abundance and half-life of methylated proteins

Methylated proteins are known to be involved in several pathways, such as translation [11] and RNA processing [49]. To investigate the function of the methylated proteins from yeast, gene ontology (GO) annotations for all yeast methylated proteins from FindMod analysis and Swiss-Prot were compared to non-methylated yeast proteins (Table 4). It was found that a number of biological processes were enriched with very high statistical significance, specifically translation, ribosome biogenesis and assembly, RNA metabolic process, and organelle organization and biogenesis. The molecular function of structural activity, RNA binding, and translation regulator activity were also significantly enriched. As may be expected from the above, methylated proteins were significantly enriched in the cellular components of the ribosome and cytoplasm.

Protein abundance data from Ghaemmaghami et al. (2003) [50] was used to compare the abundance of methylated proteins to non-methylated proteins. This was used to determine if lower abundance proteins, more likely to be involved in signal transduction and regulation [51], are methylated. Methylated proteins were found to have a higher median abundance of 11500 , as compared to non-methylated proteins, which had a median abundance of 2220 ( $\mathrm{p}<0.0001$, Figure $3 a)$. Despite this, several methylated proteins of low abundance were seen including 5 proteins of less than 1000 molecules per cell. These included Snf2p (217 copies/cell), Snu114p (300 copies/cell), Mrpl20p (358 copies/cell), and Rpl3p (450 copies/cell). Examples of 
Table 1 List of methylated proteins and methylation sites discovered by FindMod.

\begin{tabular}{|c|c|c|c|}
\hline Gene name & $\begin{array}{l}\text { Swiss-Prot } \\
\text { accession }\end{array}$ & Description & Methylated residues $^{a}$ \\
\hline ARC40 & P38328 & Actin-related protein $2 / 3$ complex subunit 1 & mK121 \\
\hline ATP2 & P00830 & ATP synthase subunit beta, mitochondrial precursor & mK196 \\
\hline CDC11 & P32458 & Cell division control protein 11 & $\mathrm{dR} 35$ \\
\hline DIP2 & Q12220 & U3 small nucleolar RNA-associated protein 12 & mK350 \\
\hline DNF1 & P32660 & Probable phospholipid-transporting ATPase DNF1 & mK541 \\
\hline ECM29 & P38737 & Proteasome component ECM29 & $\mathrm{mR} 542, \mathrm{dR} 1112$ \\
\hline EDE1 & P34216 & EH domain-containing and endocytosis protein 1 & $\mathrm{mR} 252$ \\
\hline EMG1 & Q06287 & Essential for mitotic growth 1 & mK147 \\
\hline ERB1 & Q04660 & Ribosome biogenesis protein ERB1 & mK577, mK581 \\
\hline FKS1 & P38631 & 1,3-beta-glucan synthase component FKS1 & $\begin{array}{l}\text { mR946, dR946, dR952, mR962, dR962, } \\
\text { dR1527 }\end{array}$ \\
\hline GCD10 & P41814 & $\begin{array}{l}\text { tRNA (adenine-N(1)-)-methyltransferase non-catalytic subunit } \\
\text { TRM6 }\end{array}$ & mK436, mR447 \\
\hline GCN1 & P33892 & Translational activator GCN1 & dK1446 \\
\hline GCN20 & P43535 & Protein GCN20 & dK656 \\
\hline GUS1 & P46655 & Glutamyl-tRNA synthetase, cytoplasmic & mR371 \\
\hline HAS1 & Q03532 & ATP-dependent RNA helicase HAS1 & $\mathrm{dK} 444$ \\
\hline IMD3 & P50095 & Probable inosine-5'-monophosphate dehydrogenase IMD3 & mR168 \\
\hline ISW1 & P38144 & ISWI chromatin-remodeling complex ATPase ISW1 & $\mathrm{mK} 14$ \\
\hline LEA1 & Q08963 & U2 small nuclear ribonucleoprotein $A^{\prime}$ & $\mathrm{dR} 141$ \\
\hline MPG1 & P41940 & Mannose-1-phosphate guanyltransferase & dK299 \\
\hline MRPL17 & P36528 & 54 S ribosomal protein L17, mitochondrial precursor & mK70 \\
\hline MRPL20 & P22354 & 54 S ribosomal protein $\mathrm{L} 20$, mitochondrial precursor & mK104 \\
\hline NIP1 & P32497 & Eukaryotic translation initiation factor 3 subunit $C$ & mK514 \\
\hline NOC2 & P39744 & Nucleolar complex protein 2 & mK384 \\
\hline NOG2 & P53742 & Nucleolar GTP-binding protein 2 & dR336 \\
\hline NOT1 & P25655 & General negative regulator of transcription subunit 1 & mR256 \\
\hline POL12 & P38121 & DNA polymerase alpha subunit B & mK84 \\
\hline PRP43 & P53131 & Pre-mRNA-splicing factor ATP-dependent RNA helicase PRP43 & dK662 \\
\hline PRT1 & P06103 & Eukaryotic translation initiation factor 3 subunit B & mR572 \\
\hline PSD2 & P53037 & Phosphatidylserine decarboxylase proenzyme 2 precursor & $\mathrm{mR} 252$ \\
\hline PYK1 & P00549 & Pyruvate kinase 1 & $\mathrm{mR} 216, \mathrm{dR} 216$ \\
\hline RPA2 & P22138 & DNA-directed RNA polymerase I subunit RPA2 & dK513 \\
\hline RPB2 & P08518 & DNA-directed RNA polymerase II subunit RPB2 & mR496 \\
\hline RPL16A & P26784 & 605 ribosomal protein L16-A & $\mathrm{dK} 148$ \\
\hline $\begin{array}{l}\text { RPL18A, } \\
\text { RPL18B }\end{array}$ & P07279 & $60 S$ ribosomal protein L18 & mR105 \\
\hline RPL1A, RPL1B & P53030 & 605 ribosomal protein L1 & dK207 \\
\hline $\begin{array}{l}\text { RPL20A, } \\
\text { RPL20B }\end{array}$ & POC210 & $60 S$ ribosomal protein $L 20$ & dK47 \\
\hline $\begin{array}{l}\text { RPL27A, } \\
\text { RPL27B }\end{array}$ & $\mathrm{POC} 2 \mathrm{H} 6, \mathrm{POC} 2 \mathrm{H} 7$ & $60 S$ ribosomal protein $L 27$ & $\mathrm{dR} 15, \mathrm{dK} 133$ \\
\hline RPL2A, RPL2B & P05736 & 605 ribosomal protein $L 2$ & $d R 21$ \\
\hline RPL3 & P14126 & 605 ribosomal protein $\mathrm{L} 3$ & mR275, dK384 \\
\hline RPL4A & P10664 & $60 S$ ribosomal protein $L 4-A$ & dR84, mK104 \\
\hline RPL7A & P05737 & 605 ribosomal protein $L 7-A$ & $\mathrm{mR} 218$ \\
\hline RPL7B & Q12213 & 605 ribosomal protein L7-B & mR218 \\
\hline
\end{tabular}


Table 1: List of methylated proteins and methylation sites discovered by FindMod. (Continued)

\begin{tabular}{|c|c|c|c|}
\hline RPL8B & P29453 & 605 ribosomal protein $L 8-B$ & $\mathrm{mK} 15, \mathrm{mK} 43, \mathrm{dK} 241$ \\
\hline RPN2 & P32565 & $26 \mathrm{~S}$ proteasome regulatory subunit RPN2 & mK376 \\
\hline $\begin{array}{l}\text { RPS11A, } \\
\text { RPS11B }\end{array}$ & P26781 & $40 S$ ribosomal protein $S 11$ & mR67 \\
\hline RPS13 & P05756 & $40 \mathrm{~S}$ ribosomal protein $\mathrm{S} 13$ & mK140 \\
\hline RPS17A & P02407 & $40 S$ ribosomal protein S17-A & dK59 \\
\hline RRP5 & Q05022 & rRNA biogenesis protein RRP5 & $\mathrm{dR} 215, \mathrm{dK} 769$ \\
\hline RSC1 & P53236 & Chromatin structure-remodeling complex subunit RSC1 & mR454 \\
\hline RSC30 & P38781 & Chromatin structure-remodeling complex protein RSC30 & mR692 \\
\hline RVB2 & Q12464 & RuvB-like protein 2 & mK412 \\
\hline SKI3 & P17883 & Superkiller protein 3 & dK1088 \\
\hline SMB1 & P40018 & Small nuclear ribonucleoprotein-associated protein B & mK138, mK145 \\
\hline SNF2 & P22082 & Transcription regulatory protein SNF2 & dK1028 \\
\hline SNU114 & P36048 & 114 kDa U5 small nuclear ribonucleoprotein component & dK356, mK935 \\
\hline SSB1 & P11484 & Heat shock protein SSB1 & dR513 \\
\hline SSB2 & P40150 & Heat shock protein SSB2 & dR513 \\
\hline TDH3 & P00359 & Glyceraldehyde-3-phosphate dehydrogenase 3 & $\mathrm{dR} 11$ \\
\hline TIF32 & P38249 & Eukaryotic translation initiation factor 3 subunit A & dK192 \\
\hline TUB2 & P02557 & Tubulin beta chain & $\mathrm{dR} 318$ \\
\hline URA7 & P28274 & CTP synthase 1 & $\mathrm{dK} 28$ \\
\hline USO1 & P25386 & Intracellular protein transport protein USO1 & mK119 \\
\hline UTP22 & P53254 & U3 small nucleolar RNA-associated protein 22 & mK1158 \\
\hline VPS52 & P39904 & Vacuolar protein sorting-associated protein 52 & mR224 \\
\hline YKU70 & P32807 & ATP-dependent DNA helicase II subunit 1 & dR549 \\
\hline YPR097W & Q06839 & PX domain-containing protein YPR097W & $\mathrm{dK} 249$ \\
\hline
\end{tabular}

a: $\mathrm{m}$, monomethylated; $d$, dimethylated

proteins with high abundance are $\mathrm{Rp} 1 \mathrm{Bp}(265,000$ copies/cell) and Tdh3p (169,000 copies/cell).

The methylation of lysine residues has been suggested to block their ubiquitination, leading to a longer protein half-life [52]. To investigate this possibility, protein halflife data from Belle et al. (2006) [53] was used to compare the half-life of lysine-methylated proteins to nonmethylated proteins. Interestingly, we found methylated proteins had a longer median half-life of 66 minutes, as compared to 43 minutes for non-methylated proteins ( $\mathrm{p}$ $=0.012$, Figure $3 \mathrm{~b}$ ). A striking difference between the methylated and non-methylated proteins was the absence of a group of proteins with very short half-life (see arrow in Figure 3b). Despite this, our approach also identified 18 methylated proteins with half-life less than 60 minutes. Examples of methylated proteins with shorter half-lives are Rrp5p (15 minutes), Ski3p (32 minutes), and Snu114p (52 minutes). Examples of proteins with long half-life are Utp22p (13,266 minutes) and Atp2p (6,627 minutes), although we note that these numbers may be erroneous estimations in the Belle $e t$ al. study (2006) [53]. Although the abundance and halflives of methylated proteins could be analysed more precisely by comparing methylated proteins to other proteins from the same GO slim biological process, this approach was limited by the relatively small number of methylated proteins (66 proteins) in the dataset. Methylated proteins mapped to 33 gene ontology biological process categories, with an average of 2 proteins per category, which was unsuitable for appropriate statistical analyses.

\section{Interplay of methylation and other post-translational modifications}

To see if lysine methylation might block ubiquitination, the Ubipred software [54] was used to predict if known methylated lysine sites are also subject to ubiquitination. The Ubipred software has an accuracy of $84.4 \%$ and is thus sufficiently reliable for this test. It was found that $43 \%$ of high-confidence lysine methylation sites were also predicted to be ubiquitination sites. This result lends support to the hypothesis that methylation might block ubiquitination, potentially prolonging the half-life of lysine-methylated proteins.

It has recently been reported that the methylation of arginine can regulate the phosphorylation (or dephosphorylation) of some proteins [55-61]. To investigate 
Table 2 True positive rate at mass tolerance of $0.04 \mathrm{Da}$.

\begin{tabular}{|c|c|c|c|c|}
\hline $\begin{array}{l}\text { Type of } \\
\text { methylation }\end{array}$ & $\begin{array}{l}\text { True positive rate } \\
\text { (\%) }\end{array}$ & $\begin{array}{l}\text { No. of methylation sites correctly } \\
\text { matched }\end{array}$ & $\begin{array}{l}\text { No. of methylation sites } \\
\text { tested }\end{array}$ & $\begin{array}{l}\text { No. of peptides } \\
\text { tested }\end{array}$ \\
\hline \multicolumn{5}{|c|}{ a) Non-redundant known mono- and di-methylation } \\
\hline Monomethyl-K & 100 & 27 & 466 & 1,201 \\
\hline Dimethyl-K & 98 & 89 & 280 & 699 \\
\hline Monomethyl-R & N.D. ${ }^{a}$ & N.D. ${ }^{a}$ & 3 & 6 \\
\hline Dimeth-R & 76 & 28 & 137 & 495 \\
\hline \multicolumn{5}{|c|}{ b) Artificial mono- and di-methylation } \\
\hline Monomethyl-K & 78 & 217 & 11,377 & 30,782 \\
\hline Dimethyl-K & 89 & 3,673 & 11,377 & 30,691 \\
\hline Monomethyl-R & 90 & 453 & 6,941 & 18,728 \\
\hline Dimethyl-R & 90 & 2,140 & 6,902 & 18,594 \\
\hline
\end{tabular}

a: N.D. - not determined

whether there is evidence of interplay between arginine methylation and phosphorylation in S. cerevisiae, we examined the proportion of arginine-methylated proteins that are known to be phosphorylated in databases and in the literature. It was found that 94\% (30/32) of arginine-methylated yeast proteins are known to be phosphorylated. This is a considerable increase over the $38 \%(2,548 / 6,709)$ of all S. cerevisiae proteins known to be phosphorylated and suggests a possible interplay of arginine methylation and phosphorylation [55-61].

Arginine and lysine methylation motifs

To determine if methylation sites are enriched in specific sequence-motifs, all yeast methylation sites from FindMod analysis and the Swiss-Prot database were analysed to find enriched sequence-motifs. Methionine was found to be at position -1 from lysine methylation in 5 FindMod sites and two additional methylation sites previously documented in S. cerevisiae (Table 5). This presence of methylation was of very high statistical significance $\left(\mathrm{p}=1.18 \times 10^{-6}\right)$ as compared to that expected in any random sequence of yeast proteins. By contrast, residues found to be significantly enriched adjacent to arginine methylation included $\mathrm{W}$ at position $-4\left(\mathrm{p}=1.50 \times 10^{-7}\right)$, and $\mathrm{G}$ at position $-3(\mathrm{p}=6.08 \times$ $\left.10^{-6}\right)$. While it was previously known that arginine methylation is found in RGG motifs, Wooderchak et al. (2008) [62] showed that arginine methylation is also found in RXG and RGX motifs. No known S. cerevisiae methylation sites documented in Swiss-Prot contained the RGG, RGX, or RXG-motifs. However, FindMod found 7 methylation sites with the RXG or RGX motifs. Two methylation sites, Tdh3p dimethyl-R11 and Rpl4Ap dimethyl-R84, matched to the GXXRXG motif, which conforms with the known RXG motif and the additional GXXR motif found in this study. Three methylation sites had the novel WXXXR motif.

\section{Discussion}

\section{Large-scale discovery of lysine and arginine methylation} sites

In this study, 45 lysine methylation sites and 38 arginine methylation sites were identified in 66 proteins in the $S$. cerevisiae proteome. These include 4 proteins previously known to be methylated in yeast or in other organisms and 15 proteins that are functionally related to others known to be methylated. Our findings support earlier studies [31-33] that suggested methylation to be quite widespread. Whilst many of our methylation sites are novel and have not been confirmed by MS-MS, the filters and replicate analyses we used in association with the FindMod tool provided a robust means by which protein methylation could be detected. The false positive rate was estimated to be $11 \%$ at $0.04 \mathrm{Da}$ mass error. Notwithstanding this, it should be noted that whilst we did study 2,607 proteins from yeast, this is only $\sim 40 \%$ of the total yeast proteome. Therefore, we expect that up

Table 3 Methylated proteins identified independently by both FindMod and described in the literature.

\begin{tabular}{llr}
\hline Ordered locus name (Swiss-Prot accession) & Protein name & Literature $^{a^{2}}$ \\
\hline YDL229W (P11484) & Ssb1p & Wang and Lazarides [48], Wang et al. [47], Iwabata et al. [33] \\
YNL209W (P40150) & Ssb2p & Wang and Lazarides [48], Wang et al. [47], Iwabata et al. [33] \\
YPR080W, YBR118W (P02994) & Tef1p/Tef2p/eEF1ap & Cavallius et al. [16], Iwabata et al. [33] \\
YBL087C, YER117W (P04451) & Rpl23A/Rpl23B & Porras-Yakushi et al. [14] \\
\hline YFL037W (P02557) & Tub2p & Iwabata et al. [33] \\
\hline
\end{tabular}

a: Proteins previously known to be methylated in yeast and in other organisms 
Table 4 Methylated proteins from yeast are enriched in specific processes, functions and components.

\begin{tabular}{|c|c|c|c|c|c|c|}
\hline Rank & Term (GO ID) & $\mathrm{n}_{1,1}{ }^{\mathrm{a}}$ & $\mathrm{n}_{1,2} \mathrm{~b}^{\mathrm{b}}$ & $\mathrm{n}_{2,1}{ }^{\mathrm{c}}$ & $\mathrm{n}_{2,2}{ }^{\mathrm{d}}$ & Corrected $p$-value \\
\hline \multicolumn{7}{|c|}{ Biological process } \\
\hline 1 & Translation (6412) & 37 & 48 & 305 & 5712 & 3.57 e-23 \\
\hline 2 & Ribosome biogenesis and assembly (42254) & 20 & 65 & 311 & 5706 & 5.03 e-7 \\
\hline 3 & RNA metabolic process (16070) & 21 & 64 & 664 & 5353 & 0.01 \\
\hline 4 & Organelle organization and biogenesis (6996) & 30 & 55 & 1230 & 4787 & 0.04 \\
\hline \multicolumn{7}{|c|}{ Molecular function } \\
\hline 1 & Structural molecule activity (5198) & 31 & 54 & 304 & 5712 & $3.95 \mathrm{e}-17$ \\
\hline 2 & Translation regulator activity (45182) & 5 & 80 & 47 & 5969 & 0.01 \\
\hline 3 & RNA binding (3723) & 10 & 75 & 225 & 5791 & 0.03 \\
\hline \multicolumn{7}{|c|}{ Cellular component } \\
\hline 1 & Ribosome (5840) & 33 & 52 & 307 & 5710 & 5.56 e-19 \\
\hline 2 & Cytoplasm (5737) & 59 & 26 & 2701 & 3316 & 1.05 e-4 \\
\hline
\end{tabular}

a: Number of methylated proteins with this GO slim term

b: Number of non-methylated proteins with this $\mathrm{GO}$ term

c: Number of methylated proteins with other GO slim term

d: Number of non-methylated proteins with other GO slim term

to $60 \%$ of methylated proteins would have been missed. Further methylation sites may have been missed due to difficulties in mass spectrometric detection; an example is methylarginine, which is often found in arginine- and glycine-rich regions that produce tryptic peptides that are too small for routine MALDI-TOF analysis.

Discovery rates may reflect the sub-stoichiometric nature of methylation

Previous research has highlighted that methylated peptides are difficult to discover [32] and this is made more difficult because methylation is sub-stoichiometric [34].
For example, sub-stoichiometric levels of methylations were observed in the human heterogeneous nuclear ribonucleoprotein K (hnRNP K), in which < $33 \%$ of hnRNP K were asymmetrically dimethylated at R303, and $<10 \%$ were monomethylated at R287 [56]. Our results from FindMod analysis support these observations since the proportion of methylated peptides seen for any protein was very low. The sub-stoichiometric nature of methylation events was also supported by a weak but significant correlation between the discovery rates of modified and unmodified paired peptides.

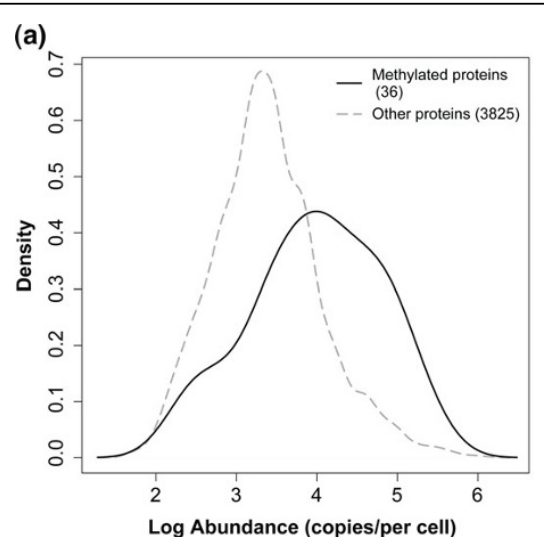

(b)

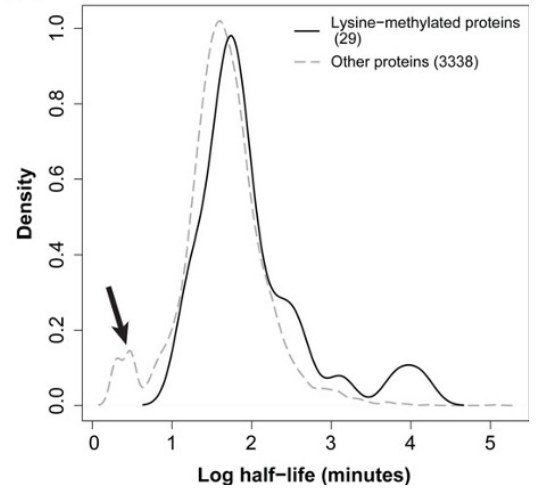

Figure 3 Distribution of abundance of methylated proteins and half-life of lysine-methylated proteins, versus non-methylated proteins. a) The $x$-axis represents protein abundance, in copies per cell, as log base 10. The abundance of methylated proteins is represented with a solid line, while the abundance of non-methylated proteins is represented with a dotted line. b) The x-axis represents protein half-life, minutes, in log base 10. The half-life of lysine-methylated proteins is represented with a solid line, while the half-life of non-methylated proteins is represented with a dotted line. The arrow points to a group of proteins with very short half-life, seen only in 'other' proteins, which are likely to be unmethylated. Note that in both figures, 'other' proteins are those for which methylation was not found; this group may, however, contain some methylated proteins. Note also that abundance data and half-life data was not available for all yeast proteins in Belle et al. (2006) [53] and Ghaemmaghami et al. (2003) [50]. 
Table 5 Lysine and arginine methylation motifs.

\begin{tabular}{|c|c|c|c|}
\hline Gene name & Swiss-Prot accession & Methylation site $^{a}$ & Motif $^{b}$ \\
\hline \multicolumn{4}{|l|}{ MK motif } \\
\hline Gcd10p & P41814 & meth-K436 ${ }^{2}$ & RGKLHPLMTMKGGGGYLMWCH \\
\hline Pfk2p & P16862 & meth-K180 & HSYTDLAYRMKTTDTYPSLPK \\
\hline Rpl23Ap & P04451 & dimeth-K110 & GVIANPKGEMKGSAITGPVGK \\
\hline Rps17Ap & P02407 & dimeth-K59² & KIAGYTTHLMKRIQKGPVRGI \\
\hline Rvb2p & Q12464 & meth-K $412^{2}$ & LISVAQQIAMKRKNNTVEVED \\
\hline Ura7p & P28274 & dimeth-K28 ${ }^{2}$ & VLASSTGMLMKTLGLKVTSIK \\
\hline Uso1p & P25386 & meth-K1192 & NGKYPSPLVMKQEKEQVDQFS \\
\hline \multicolumn{4}{|c|}{ RGx or RxG motif } \\
\hline Ecm29p & P38737 & dimeth-R1112 2 & LAKSSALWSSRKGIAFGLGAI \\
\hline Gus1p & P46655 & dimeth-R371 ${ }^{2}$ & IYRCNLTPHHRTGSTWKIYPT \\
\hline Rpl27Bp & P38706 & dimeth-R15² & LKAGKVAWWRGRYAGKKWI \\
\hline Rpl4Ap & P10664 & dimeth-R84 ${ }^{2}$ & IPRVGGGGTGRSGQGAFGNMC \\
\hline Rps11Bp & P26781 & dimeth-R $67^{2}$ & KCPFTGLVSIRGKILTGTVS \\
\hline Tdh3p & P00359 & dimeth-R $11^{2}$ & MVRVAINGFGRIGRLVMRIAL \\
\hline Tub2p & P02557 & dimeth-R318 ${ }^{2}$ & GRYLTVAAFFRGKVSVKEVED \\
\hline \multicolumn{4}{|c|}{ WxxxR and/or GxxR motif } \\
\hline Cdc11p & P32458 & dimeth-R35 ${ }^{2}$ & VMIVGQSGSGRSTFINTLCGQ \\
\hline Ecm29p & P38737 & meth-R542 ${ }^{2}$ & ARLFNIWGTVRTNRFDIIEES \\
\hline Fks1p & P38631 & meth-R946 ${ }^{2}$, dimeth-R946 ${ }^{2}$ & TLRTRIWASLRSQTLYRTISG \\
\hline Fks1p & P38631 & dimeth-R1527² & YHRNSWIGYVRMSRARITGFK \\
\hline Rpl4Ap & P10664 & dimeth-R84 ${ }^{2}$ & IPRVGGGGTGRSGQGAFGNMC \\
\hline Rpl7Ap, Rpl7Bp & P05737 & meth-R218 2 & SNPSGGWGVPRKFKHFIQGGS \\
\hline Rsc30p & P38781 & meth-R692 ${ }^{2}$ & SIKSFSSGNNRFHSNGKEFLF \\
\hline Tdh3p & P00359 & dimeth-R11 ${ }^{2}$ & MVRVAINGFGRIGRLVMRIAL \\
\hline
\end{tabular}

a: Evidence for the presence of the methylation site on this protein 1: Swiss-Prot, 2: methylation site confirmed by FindMod analysis

b: Methylation site matching the specified motif is underlined, the methylation site is highlighted in bold.

However, there may be explanations, other than biological, for the lower discovery rate of modified peptides. These included inefficient trypsin cleavage which occurs $\mathrm{C}$-terminal to methylated lysine and arginine residues [32] and differences in MALDI-ToF ionisation of the methylated peptides as seen with different proteotypic peptides [63].

Methylated proteins are involved in specific biological functions and processes, are higher in abundance and have longer half-life

Methylated proteins were found to be enriched for specific biological processes, molecular functions and subcellular localizations. Firstly, methylated proteins were enriched in translation, ribosome biogenesis and assembly. This is consistent with previous studies in which methylated proteins have been linked to translation in Escherichia coli, S. cerevisiae, and Schizosaccharomyces pombe [11]. Ribosomal proteins are also known to show lysine or arginine methylation, for example the ribosomal proteins L10a, L12, and L26a of Arabidopsis [42]. Secondly, the methylated proteins described here were found to be involved in RNA metabolic processes and are involved in RNA binding. This is consistent with the function of several proteins known to be methylated at RG-rich motifs [49]. The methylation of arginine in RGrich motifs is conserved in human, and their RNA binding activity is also conserved [32]. One such example is the fragile $\mathrm{X}$ mental retardation protein (FMRP) [25]. Thirdly, our methylated proteins were enriched in the ribosome and the cytoplasm. This is consistent with the sites of translation and association with RNA inside the cell $[22,23]$. Whilst the lack of methylated proteins enriched in the nucleus and nucleolus was not expected, these may have arisen due to our reduced set of proteins for analysis ( $40 \%$ of the yeast proteome). In addition, nuclear proteins such as histone and Npl3p are known to have peptides with multiple modification sites but these were not searched for in this study. Methylated proteins found in this study were significantly higher in abundance than proteins currently known to be non-methylated. This is partly explained by ribosomal proteins and proteins involved in translation, some 
of which we found to be methylated, being of very high abundance [50,64]. Methylated proteins were also found to be of longer average half-life. This may be due to their role in translation [11], where ribosomal proteins are generally stable [53].

\section{Interplay of methylation and other post-translational} modifications

The methylation of lysine is known to block the action of ubiquitin ligase [65], preventing proteins from degradation via the ubiquitin/proteasome system $[52,66]$. Our observation of a distinct group of low half-life proteins in $S$. cerevisiae, none of which were methylated, suggests that lysine methylation might be on many proteins and prevent their ubiquitination. The limited number of ubiquitination sites currently known on yeast proteins $[67,68]$ makes it currently difficult to check if lysine methylation, as found in this study, is found on residues that can also be poly-ubiquitinated. However, our prediction of putative ubiquitination sites [54] showed that $43 \%$ of the lysine methylation sites in 40 proteins may be ubiquitinated.

Several studies suggested that there is interplay between arginine methylation and phosphorylation of some proteins [55-61]. Arginine methylation may antagonise phosphorylation [56,57], act as a switch to enable the binding of phosphatase to encourage dephosphorylation [60], or encourage phosphorylation [59]. On the other hand, phosphorylation can either interfere with arginine methylation $[58,61]$, or promote the recruitment of arginine methyltransferase [55]. We found that the majority of arginine-methylated proteins in our study (30 out of 32 or $94 \%$ ) are known from the literature to be phosphorylated, suggesting an interplay between arginine methylation and phosphorylation in these proteins. However these arginine methylation and phosphorylation sites were not necessarily directly adjacent in the protein sequence.

\section{Arginine and lysine methylation motifs}

Motif analysis showed that many methylation sites described here conform with previously known motifs. For example, 7 arginine methylation sites discovered by FindMod conformed with the known RXG and RGX motifs [62]. Arginine methylation sites were also enriched in GXXR motifs, which correlated with the enrichment of glycine residues nearby arginine methylation sites [69]. In addition, two experimentally verified methylated sites in Pfk2p and Rpl23Ap annotated in Swiss-Prot along with 5 FindMod sites suggests the existence of a MK lysine methylation motif. The discovery of the novel enriched methylation motif WXXXR supports the possibility that there are more methylation sites to be found in S. cerevisiae. These also raise an interesting question concerning which motifs are methylated by specific methyltransferases. Methyltransferases responsible for most methylation sites are also unknown (e.g. Tef1p K30, Pfk2p K180), and the function of several methyltransferase proteins in $S$. cerevisiae remain poorly characterized [13]. Therefore, more experiments are required to elucidate the function of methylation in S. cerevisiae.

\section{Conclusions}

This study is a step towards the definition of the methyl proteome of $S$. cerevisiae. It will be useful to guide future experiments on its predominance and role in the cell. For example, experiments are needed to elucidate the function of methylation and how each site is regulated, which with the exception of histone methylation is largely unknown. Secondly, experiments to investigate whether methylation sites overlap with poly-ubiquitination sites, and therefore prevent protein degradation via the ubiquitin/proteasome pathway could be undertaken. Thirdly, it will be important to understand whether the functions of methylated proteins are co-regulated by ubiquitination, phosphorylation or other post-translational modifications. Finally, the ultimate goal in studying methylation should be to build networks of methylated proteins, their interaction partners and modifying enzymes to elucidate their dynamics as a system, similar to previous work on protein phosphorylation [70-72].

\section{Methods}

\section{MALDI-ToF mass spectra for $S$. cerevisiae}

This study employed MALDI-ToF peptide mass fingerprinting spectra from the large-scale characterization of protein complexes in S. cerevisiae [38]. There were 36,854 peptide mass spectra containing 1.2 million empirical masses, with an average mass error of 0.02 $\mathrm{Da}$. These were from 2,607 proteins out of $\sim 6,500$ proteins $(40 \%)$ in the yeast proteome, whereby each protein had an average of 11 spectra or at least 3 spectra. Peptide masses corresponding to unmodified peptides or tryptic peptides of porcine trypsin were removed, as were peptides less than $500 \mathrm{Da}$.

Tailor-made mass tolerance for each empirical spectrum An error threshold was calculated for each of the 36,854 spectra; this was possible as the identity of all proteins was known. For each spectrum, the mass differences between the empirical and theoretical mass of all known unmodified peptides were calculated. The average and median mass tolerance was $0.04 \mathrm{Da}$. To ensure high accuracy of methylation discovery, only spectra with a mass error (Additional file 6) that was lower than 0.1 Da were used for the identification of methylation sites. FindMod analysis of yeast proteins

Each peptide mass spectra was analysed with FindMod [35]. A bulk submission web interface to FindMod was 
developed http://ca.expasy.org/tools/findmod/findmod_batch.html. Each FindMod query used the UniProt accession number for the protein identified through peptide mass fingerprinting (from Gavin et al., 2006) [38], the experimental peptide masses for this protein and the tailor-made mass tolerance in Da. Other FindMod parameters included the use of monoisotopic mass, a maximum of 1 missed cleavage by trypsin, no amino acid substitutions, that the peptides were $\mathrm{M}+\mathrm{H}^{+}$and could contain oxidised methionine or tryptophan. The peptide masses were matched to theoretical peptides generated from the precursor sequence. The program searched for 71 types of post-translational modifications in all experimental peptide masses [35], including mono-, di-, and tri-methylation http://www.expasy.ch/ tools/findmod/findmod_masses.html. Matches to 6 types of modifications were removed from the analyses, as they are not found in S. cerevisiae or may lead to many false positives due to their low mass; for more details see Additional file 6. The Swiss-Prot database version 51.6 and TrEMBL version 34.6 [73] were used for the FindMod matches.

\section{Filters to remove low quality methylation sites}

For the methylated peptides to be included in the analysis, they needed to pass the following 5 filters. The peptides 1) cannot be an unmodified peptide, 2) had to contain no Asp or Glu residues, and 3) have no or one missed tryptic cleavage. In addition, 4) the peptide must have two or more overlapping peptides and at least one peptide in the overlapping peptides had to be an unambiguous peptide match. 5) When two or more modified peptides that passed filters 1-4 were also found to overlap and share the same modification site, the modification was classified as high confidence and kept. The use of overlapping peptides to improve the reliability of methylation site is facilitated by methylation sites found at the $\mathrm{C}$-terminus of peptides. Trypsin cleavage at methylated arginine and lysine has been observed in many LC-MS/MS experiments [32,74-77], and is less efficient than at non-methylated residues. A list of tryptic peptides with $\mathrm{C}$-terminal methylated amino acids, identified by LC-MS-MS, is shown in Additional file 7.

\section{Calculation of discovery rate}

The discovery rate for an unmodified peptide was calculated as the fraction of protein identifications in which the unmodified peptide is observed. In the case of duplicated genes, the counts of protein identifications were summed together because peptide mass fingerprinting cannot distinguish between proteins that do not differ in primary sequence. The discovery rate for a particular unmodified residue in the protein was calculated as the sum of the discovery rate of all the unmodified peptides that contain the residue. Discovery rates were also calculated for modified methylated peptides and methylated residues using the method as described above. Partially methylated peptides are likely to have a low discovery rate. While mass spectra with a maximum mass tolerance of $0.1 \mathrm{Da}$ were used for finding the methylation sites to limit the false positive rate, all available mass spectra with a mass tolerance of up to $1.5 \mathrm{Da}$ were used for the calculation of discovery rate. That is because more mass spectra were needed to increase the sample size for discovery rate calculation.

\section{Evaluation of the true positive and false positive rate}

Swiss-Prot entries with known lysine and arginine methylation sites were obtained from Swiss-Shop http:// au.expasy.org/swiss-shop/, for Swiss-Prot release 57.2 [73], by searching the MOD_RES field using the keywords 'methyllysine' and 'methylarginine'. S. cerevisiae proteins sequences were downloaded from Swiss-Prot by using the query 'organism:4932'. The annotation of known methylation sites were obtained from the MOD_RES field of the Swiss-Prot entry, and type of methylation were determined from the standard RESID nomenclature [78]. The proteins were processed into mature forms where appropriate; these contain no signal peptides, propeptides, intein regions, and only consists of protein chains annotated by the 'CHAIN' field of the Swiss-Prot entry. For each M or W residues in a peptide, the mass of methionine and tryptophan oxidation was added to the total mass of the peptide. Only methylated peptides with a maximum of one-missed cleavage and with masses between 500 and 3,000 Da were used. Since lysine trimethylation is near-isobaric to lysine acetylation, trimethylation was not included in the analysis. Two in silico test sets, the known methylation set and the artificial methylation set, were used to evaluate the true positive rate of FindMod for the discovery of mono- and di-methylation on arginine and lysine residues. The known methylation test set contained known lysine and arginine methylation sites from Swiss-Prot. The set of sequences from which methylation sites were found was non-redundant at the $90 \%$ identity level, generated using UniRef90 [79]. This test set included 883 known mono- and di-methylation sites. The artificial mono- and di-methylation sites on lysine and arginine residues were generated by simulated methylation on theoretical unmodified peptides. The artificial test set has more data than the known methylation test set, to allow more accurate estimation of the true positive rate. Approximately $6 \%$ of lysine residues from $S$. cerevisiae protein sequences were randomly sampled to generate artificially methylated peptides for monomethyl-K. The sampling procedure was repeated for dimethyl-K, monomethyl-R, and dimethyl$R$. The second test set was referred to as the artificial methylation set, and contained 36,594 artificial monoand di-methylation sites. 
The true positive rate of FindMod, with the 5 filters described above, was evaluated using known methylation sites and artificial methylation sites. Removal of peptides containing $\mathrm{D}$ or $\mathrm{E}$ residues were not required since no artifactual methylation on D or E residues were introduced to the in silico test sets. The true positive rate was evaluated at the mass tolerance of $0.04 \mathrm{Da}$, since this was the median mass tolerance all empirical for peptide masses [38]. For each test set, a true positive FindMod match requires the residue, sequence position and the type of methylation to be correctly matched. The true positive rate of FindMod, was calculated as the number of true positive matches divided by the sum of the number of false positive matches and the number of true positives, represented as a percentage.

\section{Arginine and lysine methylation motif analysis}

Ten amino acid residues $\mathrm{N}$-terminal and $\mathrm{C}$-terminal to each methylation site were included in the motif analysis. The number of times each amino acid occurs at each of these positions was counted. For any methylation site less than 10 residues from the $\mathrm{N}$ - or C-terminus of the protein, positions beyond the limit of the sequence were disregarded. To measure whether an amino acid was significantly enriched at each position, a $\mathrm{p}$-value was calculated using the prop.test function in the $\mathrm{R}$ statistical package. A one-sided statistical test was used, with an alternative hypothesis that there was an enrichment of amino acid frequency over the average frequency. Bonferroni's correction was used to correct the $\mathrm{p}$-value calculated by prop.test to reduce false positives.

\section{Functional analysis and statistical tests}

Functional data co-analysed with modifications were protein abundance [50], protein half-life [53], Gene Ontology (GO) slim (from Saccharomyces Genome Database, ftp://ftp.yeastgenome.org/yeast/) [80] and protein complexes [81]. Nonparametric tests were used for all statistical analyses. Protein abundance data, in copies per cell, was from Ghaemmaghammi et al. (2003) [50]. Protein half-life data, in minutes, was from Belle et al. (2006) [53]. To investigate if lysine methylation might block ubiquitination, the Ubipred software [54] was used to predict if known methylated lysine sites are also subject to ubiquitination. To investigate if arginine methylated proteins were co-regulated by phosphorylation, the Swiss-Prot database release 57.2 [73] was examined to see if methylated proteins also had experimentally determined protein threonine, serine, and tyrosine phosphorylation sites. Mann-Whitney tests, a nonparametric substitute for Student's t-test, were used to compare between two samples. Kendall's correlation coefficient, a non-parametric substitute for Pearson's correlation coefficient, was used to measure the significance of the correlation between two samples. GO slim term enrichment was assessed using Fisher's exact test and Bonferroni correction [82]. All statistical analyses were performed using the $\mathrm{R}$ statistical package version 2.2.1 [83].

\footnotetext{
Additional file 1: Examples of ambiguous and unambiguous peptide matches. This file contains examples of ambiguous and unambiguous peptide matches.

Click here for file

[http://www.biomedcentral.com/content/supplementary/1471-2164-1192-S1.DOC ]

Additional file 2: List of lysine- and arginine-methylated peptides. This file contains the list of all high confidence arginine- and lysinemethylated peptides, and their corresponding discovery rates. Click here for file

[http://www.biomedcentral.com/content/supplementary/1471-2164-1192-S2.XLS ]
}

Additional file 3: List of lysine and arginine methylation sites. This file contains the list of all high confidence methylated residues and their corresponding discovery rates.

Click here for file

[http://www.biomedcentral.com/content/supplementary/1471-2164-1192-S3.XLS ]

Additional file 4: Additional benchmarking results. Evaluation of the true positive rates of FindMod using different range of mass tolerance from 0.01 to $0.10 \mathrm{Da}$, and the known non-redundant methylation test set and the artificial methylation test set.

Click here for file

[http://www.biomedcentral.com/content/supplementary/1471-2164-1192-S4.DOC ]

Additional file 5: List of methylated peptides of Tef1p and Rpl23p discovered by FindMod. This file contains the list of methylated peptides of Tef1 $p$ and Rpl23p found by FindMod. These peptides may contain $E$ and $D$ residues, as $E$ and $D$ residues were not filtered for the analysis.

Click here for file

[http://www.biomedcentral.com/content/supplementary/1471-2164-1192-S5.DOC ]

Additional file 6: Supplementary methods. This file describes how the tailor-made error tolerances was calculated, and also provide a list of low-quality post-translational modifications that were excluded from FindMod's analysis.

Click here for file

[http://www.biomedcentral.com/content/supplementary/1471-2164-1192-S6.DOC ]

Additional file 7: List of methylation at C-terminus of peptides. This file is a list of peptides with methylation at C-terminus of peptides, collected from literature.

Click here for file

[ http://www.biomedcentral.com/content/supplementary/1471-2164-1192-S7.XLS ]

\section{Abbreviations}

Da: Daltons; GO: gene ontology; LC-MS/MS: liquid chromatography tandem mass spectrometry; MALDI-ToF: Matrix assisted laser desorption ionisation time of flight; PTM: post-translational modification.

\section{Acknowledgements}

CNIP was the recipient of Australian Postgraduate Awards. EG was supported by the Swiss Federal Government through the Federal Office of Education and Science. This research was supported in part by a University of New South Wales Faculty Research Grant, by the University of New South Wales Goldstar Scheme and the NSW State Government Science Leveraging Fund. The author thanks Timothy A. Couttas, Daniel Yagoub, Simone S. Li, and 
Adam Lee for their helpful discussions on this manuscript. We thank A.C. Gavin for facilitating access to the Cellzome peptide mass data.

\section{Author details}

${ }^{1}$ School of Biotechnology and Biomolecular Sciences, University of New South Wales, Sydney, NSW, 2052, Australia. ²Systems Biology Initiative, University of New South Wales, Sydney, NSW, 2052, Australia. ${ }^{3}$ Swiss Institute of Bioinformatics, Swiss-Prot Group, CMU - 1, rue Michel Servet, CH-1211 Geneva 4, Switzerland.

\section{Authors' contributions}

CNIP designed the method for searching arginine and lysine methylation sites using FindMod, performed the statistical and bioinformatics analyses, and wrote the manuscript. EG implemented the FindMod bulk submission program. MRW supervised the project and critically reviewed the manuscript. All authors read and approved the manuscript.

\section{Received: 12 November 2009}

Accepted: 5 February 2010 Published: 5 February 2010

\section{References}

1. Grillo MA, Colombatto S: S-adenosylmethionine and protein methylation. Amino Acids 2005, 28(4):357-362.

2. Strahl BD, Allis CD: The language of covalent histone modifications. Nature 2000, 403(6765):41-45

3. Garcia BA, Hake SB, Diaz RL, Kauer M, Morris SA, Recht J, Shabanowitz J, Mishra N, Strahl BD, Allis CD, Hunt DF: Organismal differences in posttranslational modifications in histones $\mathrm{H} 3$ and $\mathrm{H} 4$. The Journal of biological chemistry 2007, 282(10):7641-7655.

4. Pokholok DK, Harbison CT, Levine S, Cole M, Hannett NM, Lee TI, Bell GW, Walker K, Rolfe PA, Herbolsheimer E, Zeitlinger J, Lewitter F, Gifford DK, Young RA: Genome-wide map of nucleosome acetylation and methylation in yeast. Cell 2005, 122(4):517-527.

5. Briggs SD, Xiao T, Sun ZW, Caldwell JA, Shabanowitz J, Hunt DF, Allis CD, Strahl BD: Gene silencing: trans-histone regulatory pathway in chromatin. Nature 2002, 418(6897):498

6. Frederiks F, Tzouros M, Oudgenoeg $G$, van Welsem T, Fornerod M Krijgsveld J, van Leeuwen F: Nonprocessive methylation by Dot1 leads to functional redundancy of histone $\mathrm{H} 3 \mathrm{~K} 79$ methylation states. Nature structural \& molecular biology 2008, 15(6):550-557.

7. van Leeuwen F, Gafken PR, Gottschling DE: Dot1p modulates silencing in yeast by methylation of the nucleosome core. Cell 2002, 109(6):745-756.

8. San-Segundo PA, Roeder GS: Role for the silencing protein Dot1 in meiotic checkpoint control. Mol Biol Cell 2000, 11(10):3601-3615.

9. Giannattasio M, Lazzaro F, Plevani P, Muzi-Falconi M: The DNA damage checkpoint response requires histone $\mathrm{H} 2 \mathrm{~B}$ ubiquitination by Rad6-Bre1 and H3 methylation by Dot1. The Journal of biological chemistry 2005, 280(11):9879-9886

10. Wysocki R, Javaheri A, Allard S, Sha F, Cote J, Kron SJ: Role of Dot1dependent histone $\mathrm{H} 3$ methylation in $\mathrm{G} 1$ and $\mathrm{S}$ phase DNA damage checkpoint functions of Rad9. Molecular and cellular biology 2005, 25(19):8430-8443.

11. Polevoda B, Sherman F: Methylation of proteins involved in translation. Mol Microbiol 2007, 65(3):590-606

12. Lhoest J, Lobet $Y$, Costers $E$, Colson C: Methylated proteins and amino acids in the ribosomes of Saccharomyces cerevisiae. Eur J Biochem 1984, 141(3):585-590.

13. Porras-Yakushi TR, Whitelegge JP, Clarke S: A novel SET domain methyltransferase in yeast: Rkm2-dependent trimethylation of ribosomal protein L12ab at lysine 10 . The Journal of biological chemistry 2006, 281(47):35835-35845

14. Porras-Yakushi TR, Whitelegge JP, Clarke S: Yeast ribosomal/cytochrome c SET domain methyltransferase subfamily: identification of Rpl23ab methylation sites and recognition motifs. The Journal of biological chemistry 2007, 282(17):12368-12376.

15. Itoh T, Wittmann-Liebold B: The primary structure of protein 44 from the large subunit of yeast ribosomes. FEBS Lett 1978, 96(2):399-402.

16. Cavallius J, Zoll W, Chakraburtty K, Merrick WC: Characterization of yeast EF-1 alpha: non-conservation of post-translational modifications. Biochimica et biophysica acta 1993, 1163(1):75-80.
17. Xu C, Henry PA, Setya A, Henry MF: In vivo analysis of nucleolar proteins modified by the yeast arginine methyltransferase Hmt1/Rmt1p. RNA 2003, 9(6):746-759.

18. Russell ID, Tollervey D: NOP3 is an essential yeast protein which is required for pre-rRNA processing. J Cell Biol 1992, 119(4):737-747.

19. Kondo K, Inouye M: Yeast NSR1 protein that has structural similarity to mammalian nucleolin is involved in pre-rRNA processing. The Journal of biological chemistry 1992, 267(23):16252-16258.

20. Lee WC, Zabetakis D, Melese T: NSR1 is required for pre-rRNA processing and for the proper maintenance of steady-state levels of ribosomal subunits. Molecular and cellular biology 1992, 12(9):3865-3871.

21. Loo S, Laurenson P, Foss M, Dillin A, Rine J: Roles of ABF1, NPL3, and YCL54 in silencing in Saccharomyces cerevisiae. Genetics 1995, 141(3):889-902.

22. Green DM, Marfatia KA, Crafton EB, Zhang X, Cheng $X$, Corbett AH: Nab2p is required for poly $(A)$ RNA export in Saccharomyces cerevisiae and is regulated by arginine methylation via Hmt1p. The Journal of biological chemistry 2002, 277(10):7752-7760.

23. Shen EC, Henry MF, Weiss VH, Valentini SR, Silver PA, Lee MS: Arginine methylation facilitates the nuclear export of hnRNP proteins. Genes \& development 1998, 12(5):679-691.

24. Kiledjian M, Dreyfuss G: Primary structure and binding activity of the hnRNP U protein: binding RNA through RGG box. The EMBO journal 1992, 11(7):2655-2664

25. Dolzhanskaya N, Merz G, Aletta JM, Denman RB: Methylation regulates the intracellular protein-protein and protein-RNA interactions of FMRP. J Cell Sci 2006, 119(Pt 9):1933-1946.

26. McBride AE, Cook JT, Stemmler EA, Rutledge KL, McGrath KA, Rubens JA: Arginine methylation of yeast mRNA-binding protein Npl3 directly affects its function, nuclear export, and intranuclear protein interactions. The Journal of biological chemistry 2005, 280(35):30888-30898.

27. Cote J, Richard S: Tudor domains bind symmetrical dimethylated arginines. The Journal of biological chemistry 2005, 280(31):28476-28483.

28. Bedford MT, Frankel A, Yaffe MB, Clarke S, Leder P, Richard S: Arginine methylation inhibits the binding of proline-rich ligands to Src homology 3 , but not WW, domains. The Journal of biological chemistry 2000 , 275(21):16030-16036

29. McBride $A E$, Silver PA: State of the arg: protein methylation at arginine comes of age. Cell 2001, 106(1):5-8.

30. Bedford MT, Clarke SG: Protein arginine methylation in mammals: who, what, and why. Molecular cell 2009, 33(1):1-13

31. Boisvert FM, Cote J, Boulanger MC, Richard S: A proteomic analysis of arginine-methylated protein complexes. Mol Cell Proteomics 2003, 2(12):1319-1330

32. Ong SE, Mittler G, Mann M: Identifying and quantifying in vivo methylation sites by heavy methyl SILAC. Nat Methods 2004, 1(2):119-126.

33. Iwabata H, Yoshida M, Komatsu Y: Proteomic analysis of organ-specific post-translational lysine-acetylation and -methylation in mice by use of anti-acetyllysine and -methyllysine mouse monoclonal antibodies. Proteomics 2005, 5(18):4653-4664.

34. Mann M, Jensen ON: Proteomic analysis of post-translational modifications. Nat Biotechnol 2003, 21(3):255-261.

35. Wilkins MR, Gasteiger E, Gooley AA, Herbert BR, Molloy MP, Binz PA, Ou K, Sanchez JC, Bairoch A, Williams KL, Hochstrasser DF: High-throughput mass spectrometric discovery of protein post-translational modifications. $J \mathrm{Mo}$ Biol 1999, 289(3):645-657.

36. Bandeira N, Tsur D, Frank A, Pevzner PA: Protein identification by spectral networks analysis. Proceedings of the National Academy of Sciences of the United States of America 2007, 104(15):6140-6145.

37. Tsur D, Tanner S, Zandi E, Bafna V, Pevzner PA: Identification of posttranslational modifications by blind search of mass spectra. Nat Biotechnol 2005, 23(12):1562-1567

38. Gavin AC, Aloy P, Grandi P, Krause R, Boesche M, Marzioch M, Rau C, Jensen LJ, Bastuck S, Dumpelfeld B, Edelmann A, Heurtier MA, Hoffman V, Hoefert C, Klein K, Hudak M, Michon AM, Schelder M, Schirle M, Remor M, Rudi T, Hooper S, Bauer A, Bouwmeester T, Casari G, Drewes G, Neubauer G, Rick JM, Kuster B, Bork P, et al: Proteome survey reveals modularity of the yeast cell machinery. Nature 2006, 440(7084):631-636.

39. Jung SY, Li Y, Wang Y, Chen Y, Zhao Y, Qin J: Complications in the assignment of 14 and 28 Da mass shift detected by mass spectrometry 
as in vivo methylation from endogenous proteins. Anal Chem 2008, 80(5):1721-1729

40. Lee SW, Berger SJ, Martinovic S, Pasa-Tolic L, Anderson GA, Shen Y, Zhao R, Smith RD: Direct mass spectrometric analysis of intact proteins of the yeast large ribosomal subunit using capillary LC/FTICR. Proceedings of the National Academy of Sciences of the United States of America 2002, 99(9):5942-5947.

41. Sadaie M, Shinmyozu K, Nakayama J: A conserved SET domain methyltransferase, Set11, modifies ribosomal protein Rpl12 in fission yeast. The Journal of biological chemistry 2008, 283(11):7185-7195.

42. Carroll AJ, Heazlewood JL, Ito J, Millar AH: Analysis of the Arabidopsis cytosolic ribosome proteome provides detailed insights into its components and their post-translational modification. Mol Cell Proteomics 2008, 7(2):347-369.

43. Goldenberg CJ, Eliceiri GL: Methylation of ribosomal proteins in HeLa cells. Biochimica et biophysica acta 1977, 479(2):220-234.

44. Shin HS, Jang CY, Kim HD, Kim TS, Kim S, Kim J: Arginine methylation of ribosomal protein S3 affects ribosome assembly. Biochemical and biophysical research communications 2009, 385(2):273-278.

45. Scolnik PA, Eliceiri GL: Methylation sites in HeLa cell ribosomal proteins. Eur J Biochem 1979, 101(1):93-101.

46. Swiercz R, Person MD, Bedford MT: Ribosomal protein $S 2$ is a substrate for mammalian PRMT3 (protein arginine methyltransferase 3). The Biochemical journal 2005, 386(Pt 1):85-91.

47. Wang C, Lin JM, Lazarides E: Methylations of 70,000-Da heat shock proteins in 3T3 cells: alterations by arsenite treatment, by different stages of growth and by virus transformation. Arch Biochem Biophys 1992, 297(1):169-175.

48. Wang C, Lazarides $\mathrm{E}$ : Arsenite-induced changes in methylation of the 70,000 dalton heat shock proteins in chicken embryo fibroblasts. Biochemical and biophysical research communications 1984, 119(2):735-743.

49. Yu MC, Bachand F, McBride AE, Komili S, Casolari JM, Silver PA: Arginine methyltransferase affects interactions and recruitment of mRNA processing and export factors. Genes \& development 2004, 18(16):2024-2035.

50. Ghaemmaghami S, Huh WK, Bower K, Howson RW, Belle A, Dephoure N, O'Shea EK, Weissman JS: Global analysis of protein expression in yeast. Nature 2003, 425(6959):737-741.

51. Bedford MT, Richard S: Arginine methylation an emerging regulator of protein function. Molecular cell 2005, 18(3):263-272.

52. Desiere F, Deutsch EW, Nesvizhskii Al, Mallick P, King NL, Eng JK, Aderem A, Boyle R, Brunner E, Donohoe S, Fausto N, Hafen E, Hood L, Katze MG, Kennedy KA, Kregenow F, Lee H, Lin B, Martin D, Ranish JA, Rawlings DJ, Samelson LE, Shiio Y, Watts JD, Wollscheid B, Wright ME, Yan W, Yang L, Yi EC, Zhang $H$, et al: Integration with the human genome of peptide sequences obtained by high-throughput mass spectrometry. Genome biology 2005, 6(1):R9.

53. Belle A, Tanay A, Bitincka L, Shamir R, O'Shea EK: Quantification of protein half-lives in the budding yeast proteome. Proc Natl Acad Sci USA 2006, 103(35):13004-13009.

54. Tung CW, Ho SY: Computational identification of ubiquitylation sites from protein sequences. BMC Bioinformatics 2008, 9:310.

55. Gupta P, Ho PC, Huq MD, Khan AA, Tsai NP, Wei LN: PKCepsilon stimulated arginine methylation of RIP140 for its nuclear-cytoplasmic export in adipocyte differentiation. PLoS One 2008, 3(7):e2658.

56. Ostareck-Lederer A, Ostareck DH, Rucknagel KP, Schierhorn A, Moritz B, Huttelmaier S, Flach N, Handoko L, Wahle E: Asymmetric arginine dimethylation of heterogeneous nuclear ribonucleoprotein $\mathrm{K}$ by proteinarginine methyltransferase 1 inhibits its interaction with c-Src. The Journal of biological chemistry 2006, 281(16):11115-11125.

57. Yamagata K, Daitoku H, Takahashi Y, Namiki K, Hisatake K, Kako K, Mukai H, Kasuya Y, Fukamizu A: Arginine methylation of FOXO transcription factors inhibits their phosphorylation by Akt. Molecular cell 2008, 32(2):221-231.

58. Yun CY, Fu XD: Conserved SR protein kinase functions in nuclear import and its action is counteracted by arginine methylation in Saccharomyces cerevisiae. J Cell Biol 2000, 150(4):707-718.

59. Chen W, Daines MO, Hershey GK: Methylation of STAT6 modulates STAT6 phosphorylation, nuclear translocation, and DNA-binding activity. $J$ Immunol 2004, 172(11):6744-6750.
60. Zhu W, Mustelin T, David M: Arginine methylation of STAT1 regulates its dephosphorylation by $T$ cell protein tyrosine phosphatase. The Journal of biological chemistry 2002, 277(39):35787-35790.

61. Hsu la W, Hsu M, Li C, Chuang TW, Lin Rl, Tarn WY: Phosphorylation of Y14 modulates its interaction with proteins involved in mRNA metabolism and influences its methylation. The Journal of biological chemistry 2005, 280(41):34507-34512.

62. Wooderchak WL, Zang T, Zhou ZS, Acuna M, Tahara SM, Hevel JM: Substrate profiling of PRMT1 reveals amino acid sequences that extend beyond the "RGG" paradigm. Biochemistry 2008, 47(36):9456-9466.

63. Mallick P, Schirle M, Chen SS, Flory MR, Lee H, Martin D, Ranish J, Raught B, Schmitt R, Werner T, Kuster B, Aebersold R: Computational prediction of proteotypic peptides for quantitative proteomics. Nat Biotechnol 2007, 25(1):125-131

64. Newman JR, Ghaemmaghami S, Ihmels J, Breslow DK, Noble M, DeRisi JL, Weissman JS: Single-cell proteomic analysis of S. cerevisiae reveals the architecture of biological noise. Nature 2006, 441(7095):840-846.

65. Michalek MT, Grant EP, Rock KL: Chemical denaturation and modification of ovalbumin alters its dependence on ubiquitin conjugation for class I antigen presentation. J Immunol 1996, 157(2):617-624.

66. Chuikov S, Kurash JK, Wilson JR, Xiao B, Justin N, Ivanov GS, McKinney K, Tempst P, Prives C, Gamblin SJ, Barlev NA, Reinberg D: Regulation of p53 activity through lysine methylation. Nature 2004, 432(7015):353-360.

67. Lu JY, Lin YY, Qian J, Tao SC, Zhu J, Pickart C, Zhu H: Functional dissection of a HECT ubiquitin E3 ligase. Mol Cell Proteomics 2008, 7(1):35-45.

68. Gupta R, Kus B, Fladd C, Wasmuth J, Tonikian R, Sidhu S, Krogan NJ, Parkinson J, Rotin D: Ubiquitination screen using protein microarrays for comprehensive identification of Rsp5 substrates in yeast. Molecular systems biology 2007, 3:116.

69. Daily KM, Radivojac P, Dunker AK: Intrinsic disorder and protein modifications: building an SVM predictor for methylation. IEEE Symposium on Computational Intelligence in Bioinformatics and Computational Biology, CIBCB 2005: November 2005 2005; San Diego, California, USA 2005, 475-481.

70. Ptacek J, Devgan G, Michaud G, Zhu H, Zhu X, Fasolo J, Guo H, Jona G, Breitkreutz A, Sopko R, McCartney RR, Schmidt MC, Rachidi N, Lee SJ, Mah AS, Meng L, Stark MJ, Stern DF, De Virgilio C, Tyers M, Andrews B, Gerstein M, Schweitzer B, Predki PF, Snyder M: Global analysis of protein phosphorylation in yeast. Nature 2005, 438(7068):679-684.

71. Linding $R$, Jensen $L$, Ostheimer GJ, van Vugt MA, Jorgensen C, Miron IM, Diella F, Colwill K, Taylor L, Elder K, Metalnikov P, Nguyen V, Pasculescu A, Jin J, Park JG, Samson LD, Woodgett JR, Russell RB, Bork P, Yaffe MB, Pawson T: Systematic discovery of in vivo phosphorylation networks. Cell 2007, 129(7):1415-1426.

72. Fiedler D, Braberg H, Mehta M, Chechik G, Cagney G, Mukherjee P, Silva AC, Shales M, Collins SR, van Wageningen S, Kemmeren P, Holstege FC, Weissman JS, Keogh MC, Koller D, Shokat KM, Krogan NJ: Functional organization of the S. cerevisiae phosphorylation network. Cell 2009, 136(5):952-963.

73. The UniProt Consortium: The Universal Protein Resource (UniProt). Nucleic acids research 2009, 37 Database: D169-174.

74. Couttas TA, Raftery MJ, Bernardini G, Wilkins MR: Immonium ion scanning for the discovery of post-translational modifications and its application to histones. J Proteome Res 2008, 7(7):2632-2641.

75. Beck HC, Nielsen EC, Matthiesen R, Jensen LH, Sehested M, Finn P, Grauslund M, Hansen AM, Jensen ON: Quantitative proteomic analysis of post-translational modifications of human histones. Mol Cell Proteomics 2006, 5(7):1314-1325.

76. Dave KA, Hamilton BR, Wallis TP, Furness SGB, Whitelaw ML, Gorman JJ: Identification of $\mathrm{N}$, Nepsilon-dimethyl-lysine in the murine dioxin receptor using MALDI-TOF/TOF- and ESI-LTQ-Orbitrap-FT-MS. Int J Mass Spec 2007, 268(2-3):168-180.

77. Wisniewski JR, Zougman A, Kruger S, Mann M: Mass spectrometric mapping of linker histone $\mathrm{H} 1$ variants reveals multiple acetylations, methylations, and phosphorylation as well as differences between cell culture and tissue. Mol Cell Proteomics 2007, 6(1):72-87.

78. Garavelli JS: The RESID Database of Protein Modifications as a resource and annotation tool. Proteomics 2004, 4(6):1527-1533.

79. Suzek BE, Huang H, McGarvey P, Mazumder R, Wu CH: UniRef: comprehensive and non-redundant UniProt reference clusters. Bioinformatics (Oxford, England) 2007, 23(10):1282-1288. 
80. Hong EL, Balakrishnan R, Dong Q, Christie KR, Park J, Binkley G, Costanzo MC, Dwight SS, Engel SR, Fisk DG, Hirschman JE, Hitz BC, Krieger CJ, Livstone MS, Miyasato SR, Nash RS, Oughtred R, Skrzypek MS, Weng S, Wong ED, Zhu KK, Dolinski K, Botstein D, Cherry JM: Gene Ontology annotations at SGD: new data sources and annotation methods. Nucleic acids research 2008, , 36 Database: D577-581.

81. Hart GT, Lee I, Marcotte ER: A high-accuracy consensus map of yeast protein complexes reveals modular nature of gene essentiality. BMC Bioinformatics 2007, 8:236.

82. Rivals I, Personnaz L, Taing L, Potier MC: Enrichment or depletion of a GO category within a class of genes: which test?. Bioinformatics (Oxford, England) 2007, 23(4):401-407.

83. R Development Core Team: R: A language and environment for statistical computing. Vienna: R Foundation for statistical computing 2005.

doi:10.1186/1471-2164-11-92

Cite this article as: Pang et al:. Identification of arginine- and lysinemethylation in the proteome of Saccharomyces cerevisiae and its functional implications. BMC Genomics 2010 11:92.

\section{Submit your next manuscript to BioMed Central} and take full advantage of:

- Convenient online submission

- Thorough peer review

- No space constraints or color figure charges

- Immediate publication on acceptance

- Inclusion in PubMed, CAS, Scopus and Google Scholar

- Research which is freely available for redistribution

Submit your manuscript at www.biomedcentral.com/submit 